\title{
The physical and electrochromic properties of Prussian Blue thin films electrodeposited on ITO electrodes
}

\author{
V. B. Isfahani ${ }^{1,2}$, N. Memarian ${ }^{1}$, Hamid Rezagholipour Dizaji ${ }^{1}$, A. Arab ${ }^{3}$, M. M. Silva ${ }^{2 *}$ \\ ${ }^{1}$ Faculty of Physics, Semnan University, P.O. Box: 35195-363, Semnan, Iran \\ ${ }^{2}$ Department of Chemistry and CQ, University of Minho, Gualtar, 4710-057 Braga,Portugal \\ ${ }^{3}$ Department of Chemistry, Semnan University, P.O. Box: 35131-19111, Semnan, Iran
}

\section{*nini@quimica.uminho.pt}

\begin{abstract}
In this article, a set of Prussian Blue (PB) thin films with different electrodeposition times $(25 \mathrm{~s}$, $50 \mathrm{~s}, 75 \mathrm{~s}, 100 \mathrm{~s}$ and $150 \mathrm{~s}$ ) in air at ambient temperature was prepared. The layers were characterized by a variety of techniques which include, field effect scanning electron microscopy, energy-dispersive X-ray spectrometer, X-ray diffraction, Fourier transform infared spectroscopy, UV-Vis spectrophotometry, and electrochemical analysis. A simple and exact electrochemical method was used to estimate the optimal voltages for coloring and bleaching of different PB layers. Controlling electrodeposition time along with applying suitable voltage enabled us to investigate and improve electrochromic properties of PB layer. The sample prepared under $75 \mathrm{~s}$ deposition time showed probably a composition intermediate between the insoluble and soluble form. Furthermore, this sample (S75) shows a better electrochromic properties. High value of electrochromic contrast $55.36 \%$ at $555 \mathrm{~nm}$ and well stability of ion exchange by cycling are the characteristics of this layer. The control of the deposition time resulted in an increase of 9.38 times of the contrast ratio and corresponding values for optical density $(\triangle O D)$ of the PB layers.
\end{abstract}


Key words: Electrodeposition; Prussian Blue; Thin film; Electrochromic properties.

\section{Introduction}

Recent interest for smart materials has been stimulated by the continuously expanding need for the possibility of their applications in a broad variety of electrochemical devices, like electrochromic devices (ECDs)[1-3] . An electrochromic (EC) material shows reversible color changes when a potential difference is applied across it: a visible and reversible variation of optical properties namely, light transmittance and/or reflectance, is shown by a material upon its electrochemical oxidation/reduction. Color changes typically range between a transparent (bleached) state and one or two colored states, corresponding to different redox conditions[4]. Today, there are many applications for EC materials in the automotive industry, manufacture of screens, design of buildings, and in particular in the green architecture.

Several electroactive species have been used as EC materials, such as inorganic transition metal oxides $\left(\mathrm{WO}_{3}, \mathrm{IrO}_{2}, \mathrm{MoO}_{3}\right)$, hexacyanomettalates such as $\left(\left[\mathrm{Fe}^{3+} \mathrm{Fe}^{2+}(\mathrm{CN})_{6}\right]^{-}\right)$which is named as Prussian Blue (PB), viologens (bipyridium compounds), and cojugated polymers[5]. In general, electrochroms can be classified into two categories of organic and inorganic materials, each of which has its own unique characteristics.

However, depending on the electrochromic material the initial state can be colored or colorless (transparent) and the former is true in the case of PB. PB is one of the inorganic EC materials, first produced in 1704 by Diesbach[6]. It is normaly blue in color and contains iron of two different states $\mathrm{Fe}^{2+}$ and $\mathrm{Fe}^{3+}$. $\mathrm{PB}$ is a well-known material whose electrochromic properties were observed in $1978[7,8]$. There are now many such compounds, all of which share the same general formula $M_{x}^{\prime}\left[M(C N)_{6}\right]_{y}$ where $\mathrm{x}$ and $\mathrm{y}$ are integers and $\mathrm{M}$ and $\mathrm{M}^{\prime}$ are transition 
metals $\left(\mathrm{Fe}^{3+}\right.$ and $\mathrm{Fe}^{2+}$ respectively in the case of $\left.\mathrm{PB}\right)$. When the metals in such compounds exist in different oxidation states, intervalence charge transfer can occur (resulting in color). PB contains a high-spin ferric ion coupled to a low-spin ferrous ion, via a bridging cyanide molecule (with the ferric ion bound to the nitrogen and the ferrous ion to the carbon) [7, 9]. However, in the presence of a suitable electrolyte, PB respectively turns colorless and green after oxidation and reduction and new materials with different optical properties can be obtained which can be very useful electrochemical reduction of PB produces Prussian white (PW), or Everett's Salt (ES), and oxidation of Prussian Blue leads to Prussian Green (PG), also known as Berlin Green. Further oxidation leads to Prussian Brown (PX), which is brown when in a bulk solid form, but yellow when in a thin film form.

Easy and inexpensive preparation of PB layer by chemical and electrochemical methods on conducting and semiconducting substrates [10], compared to the expensive physical methods as well as beautiful and functional colors of PB and its products have made it more noticeable in the manufacture of ECDs. Since PB film properties and its functionctionality are very much sensitive to parameters such as deposition condition, several research groups are engaged on producing PB layers of high quality for ECD application. Electrochemical deposition of PB has been carried out in the last few years due to their interesting electrochemical and electrochromic properties [11-14].

In the present study, we have investigated the effect of deposition time on thickness, morphology, structure, compositions, electrochemical, and electrochromic properties of PB thin films. We have demonstrated that these samples are promising materials with foreseen applications in the fields of solid state electrochemistry. The sample with electrodeposition time 75s has a good electrochromic capacity, while for longer electrodeposition times the 
electrochemical properties seem better.

\section{Experimental}

\subsection{Substrate preparation}

A conducting transparent indium tin oxide (ITO) coated glass substrate (FINE BRAND, IN-100 $10 \Omega \mathrm{cm}^{-2}$ ) with dimensions of $0.7 \times 1.5 \mathrm{~cm}^{2}$ was used as a substrate for electrodeposition of the PB films. All ITO samples were ultrasonically degreased for 10 minutes in acetone (Merck) and ethanol (Merck, 99.9\%), respectively and then rinsed with deionized water. Finally, the ITO substrates were dried at room temperature.

\subsection{Electrodeposition of PB films}

Using optimal voltage (0.4 V vs. (Saturated Calomel Electrode, SCE)) [15] for electrodeposition of PB on the surface of ITO substrate by chronoamperometry (CHA) method, five different thin PB films were prepared with deposition times of 25, 50, 75, 100, and $150 \mathrm{~s}$, which are represented by the notation S25, S50, S75, S100, and S150 (Fig. 1). The electrodepositions were done in a conventional three electrode cell including glass / ITO, SCE, and Pt plate as working, reference and counter electrodes respectively. The electrodeposition bath contains $\mathrm{HNO}_{3}(\mathrm{Merck}$, 65\%) (100 mM), $\mathrm{KNO}_{3}\left(\right.$ Merck, 99\%) (100 mM), $\mathrm{Fe}\left(\mathrm{NO}_{3}\right)_{3} .9 \mathrm{H}_{2} \mathrm{O}$ (Merck, 99\%) (10 mM) and $\mathrm{K}_{3}\left[\mathrm{Fe}(\mathrm{CN})_{6}\right](10 \mathrm{mM})$ as precursors.

The electrochemical experiments were carried out using a BHP 2066 or Ivium Stat Potentiostat/Galvanostat. Finally, the electrodeposited samples were rinsed with Milli-Q water to remove the excess of solution remained on the PB films. The change in electrodeposition time 
changes the electrochemical and morphological characteristics of prepared layers which in turn affect their electrochromic properties.

\subsection{Characterization of the PB layers}

Morphology of PB films were characterized by Field Emission Scanning Electron Microscopy (FE-SEM) by means of SIGMA VP-500 ZEISS instruments at $15 \mathrm{kV}$ accelerating voltage and by Energy-dispersive X-ray spectroscopy (EDX) using attached energy-dispersive X-ray spectrometer the elemental combination or concentrations of the layers were studied. Films structures were analyzed by X-ray diffraction (XRD) (ADVANCE-D8 model) equipped with $\mathrm{Cuk}_{\alpha}$ radiation source with $\lambda=1.5406 \AA$ and fourier transform infared (FTIR-ATR) spectra of the samples were recorded by AVATAR, Thermo. Cyclic voltammetry (CV) measurements were performed in the potential range of $+1.0 \mathrm{~V}$ to $-1.8 \mathrm{~V}$ and scan rate of $2.0 \mathrm{mV} \mathrm{s}^{-1}$ in order to investigate the electrochemical properties of samples. The CV experiments were done in a twoelectrode cell configuration containing ITO/PB layer and Pt wire electrodes. The electrolyte used in this step was an aqueous solution composed of $\mathrm{HNO}_{3}(10 \mathrm{mM})$ and $\mathrm{KNO}_{3}(10 \mathrm{mM})$.

Optical analysis of the samples has been done by a designed set up which was combination of Avantes, Avalight - DHS, AvaSpec-3648-2-USB2 and AvaSpec-NIR256-1.7. Double step chronoamperometry analysis was performed to study the switching response of the PB layers.

\section{Results and Discussion}

\subsection{FE-SEM analysis}


Fig.2 presents the cross section and surface SEM images of as deposited S75 in two different magnifications. It can be seen the layer is composed of three distinguished parts; The bottom part is the ITO substrate $\left(\mathrm{L}_{1}\right)$ and in the middle there is a compact layer of PB $\left(\mathrm{L}_{2}\right)$ that their thicknesses are $0.180 \mu \mathrm{m}$ and $0.280 \mu \mathrm{m}$, respectively. On the top of $\mathrm{L}_{2}$ layer, irregular agglomerated PB particles with the average dimension of $0.243 \mu \mathrm{m}$ dispersed throughout a developed network of cracks. These agglomerated clusters are made of some smaller particles, which are seen in Fig. 2b. This hierarchical morphology resulted in increasing the effective area of the layer for interaction with $\mathrm{K}^{+}$ions in electrolyte, this may affect on ion exchange and facilitate the movement of ions and ionic conductivity. More analysis confirmed that this structure is not appeared when applying lower deposition time (S25) and a rather compact layer of PB is formed on ITO substrate (Fig. S1 in supporting information). On the other hand, more increase in the deposition time (S100 and S150) resulted in the agglomeration in the upper layer (Figs. S2 and S3 in supporting information) and affects the performance of the film. It may be noted that the appearance of the cracks can reduce the stability of these types of films under conditions of the hydrogen peroxide electro reduction, since electrolyte as well as generated $\mathrm{OH}^{-}$ anions can easily penetrate under the PB layer, leading to the peeling off the surface [16-19].

\subsection{EDX analysis}

The EDX spectrum of synthesized PB layers (Fig. 3 and Supporting Information, S4) indicate the presence of carbon, oxygen, potassium, iron, and nitrogen elements in all samples (S25, S75, $\mathrm{S} 100$ and $\mathrm{S} 150)$. As one knows $\mathrm{Fe}_{4}\left[\mathrm{Fe}(\mathrm{CN})_{6}\right]_{3}$ and $\mathrm{KFe}\left[\mathrm{Fe}(\mathrm{CN})_{6}\right]$, are insoluble and soluble forms of PB, respectively $[20,21]$. P. R. Bueno and F. F. Ferreira [22, 23] propose that the soluble and insoluble forms are very similar and that the main change may be the presence of 
potassium cations filling the vacancies in the $\mathrm{PB}$ soluble form. The EDX data, within experimental errors, also confirmed that the PB had been synthesized. The soluble form contains potassium ions and insoluble form contains very little or no potassium ions, so it may be inferred from the images of the sample S75 (Fig. 3) that the weight of potassium ions is $2.37 \%$ in contrast, of S25, S100 and S150 (Fig. S4 in Supporting Information) that the weight of potassium ions is $23.9,13.5$ and $14.2 \%$ respectively. The present result suggests that insoluble and soluble PB coexist in the PB structure for all samples, and the sample S75 appears composed with more insoluble PB. This observation is not corroborated with eq. (2) because $\mathrm{K}^{+}$ions exist in the PB films in a relation 2:1 regarding Fe (atomic \%). The insoluble PB is electrochemically converted into the soluble PB until a stable electrochemical response is achieved [24]. However this conversion it is clearly not fully quantitative, due to the fact that the stoichiometry of the $\mathrm{PB}$ soluble form cannot exactly be described as that shown in the chemical formula, and the electroactive films probably present a composition intermediate between the insoluble and soluble form [25] For S25, S100 and S150, a large amount of potassium that can be probably related to the part of the potassium iron cyanide and/or potassium nitrate as the precursors in the initial solution that it did not participate in the chemical reactions. The presence of potassiumcontaining electrolyte in the vicinity of the exterior surface of the sample during the deposition and applying the potential on it could lead to the penetration of potassium ion into the PB network. On the other hand, the lack of sufficient dissolution of the precursors or their precipitation during the deposition process can cause some of the precursors to remain on the film without participating in reactions. The latter finding beautifully corroborates the XRD data.

\subsection{XRD analysis}


The XRD patterns of different PB layers (S25, S75, S100s, and S150) on ITO substrate in comparison with XRD of bare ITO substrate, are shown in Fig. 4. The figure exhibits in all samples we have the characteristic diffraction peaks of ITO indicating the crystalline nature of the substrate[26]. The XRD patterns of the ITO shows peak at $\approx 31^{\circ}$ corresponding to $\operatorname{In}_{2} \mathrm{O}_{3}$ [27]. Also we can see the peaks at $\approx 37^{\circ}$ and $\approx 51^{\circ}$ correspond to indium and tin, indicating a metalrich film $[28,29]$. The content of PB in the ITO is very low, and there are no very obvious differences between PB and ITO in XRD patterns. The obtained PB have peak around $12-17^{\circ}$, $21^{\circ}$ (for S25, S100 and S150), $24^{\circ}$ (for S75), $35^{\circ}$ and $51^{\circ}$, which can be assigned to the planes of face-centered-cubic lattice PB (JCPDS 73-0687) $[30,31]$ The peak at about $51^{\circ}$ for PB is shift to more positive values in comparison of peak of ITO. A closer examination showed a small peak corresponding to KNO3 at about 27.5' for S25 (standard card 01-076-1693) It seems that during the electrodeposition process a portion of $\mathrm{KNO}_{3}$ as the precursors have not been participated in the reactions and have deposited on the substrate in a crystalline form. This problem is unavoidable in the electrodeposition process, especially when the deposition time increases. These findings confirm the semi-amorphous nature of PB layers, which is in good agreement with the EDX results.

\subsection{FTIR-ATR analysis}

Fig. 5 presents the FTIR-ATR spectra of S75 and S100 as two typical PB layer with different deposition time. It is observed that in both samples the sharp peak around $2064 \mathrm{~cm}^{-1}$ corresponds to $\mathrm{Fe}^{\mathrm{II}}-\mathrm{C} \equiv \mathrm{N}-\mathrm{Fe}^{\mathrm{III}}$ stretching vibration mode that confirms the formation of $\mathrm{PB}$. The peaks around $1606 \mathrm{~cm}^{-1}$ and $1557 \mathrm{~cm}^{-1}$ for $\mathrm{S} 75$ and $1608 \mathrm{~cm}^{-1}$ and $1563 \mathrm{~cm}^{-1}$ for S100, are due to H-O$\mathrm{H}$ bending vibration mode. That shows the influence of water in PB structure and also broad 
peak around $2800 \mathrm{~cm}^{-1}$ is an evidence for surface absorbed water and hydroxyl group. It seems the peaks in 1413 and $1725 \mathrm{~cm}^{-1}$ assigned to $\mathrm{O}-\mathrm{H}$ bending mode and deformation vibration mode of water molecules, respectively [32]. For PB there are same caracteristics bands in the farinfrared region (450-650 $\left.\mathrm{cm}^{-1}\right)$ [33] and the band around $500 \mathrm{~cm}^{-1}$ in $\mathrm{S} 75$ are due the structure of $\mathrm{Fe}^{\mathrm{II}}-\mathrm{C} \equiv \mathrm{N}-\mathrm{Fe}^{\mathrm{III}}$ linkage of $\mathrm{PB}[34,35]$. This peak are expected to have relation to the presence of coprecipitated ferricyanide ion [34]

\subsection{Electrochemical analysis}

The profile of these CVs presented in Figure S5 of Supporting Information, is identical, as expected, with results are reported by R. J. Mortimer et al [36 J. Mater Chem. 15 (2005) 22262233]. Voltammograms of S25 and S100 PB samples recorded in a three electrodes cell (containing a solution of $0.1 \mathrm{M} \mathrm{HNO}_{3}$ and $0.1 \mathrm{M} \mathrm{KNO}_{3}$ ), at a scan rate of $100 \mathrm{mV} \mathrm{s}^{-1}$ and in the potential range of $-0.5 \mathrm{~V}$ to $0.7 \mathrm{~V}$ (Figure $\mathrm{S} 5$ of Supporting Information). These analyses started at $-0.5 \mathrm{~V}$ in the anodic direction, and a SCE and a platinum plate were also used as the reference and counter electrodes respectively. These observations, therefore lead us to conclude that we have successfully deposited the PB films on the ITO substrate. The observed redox peak in these $\mathrm{CVs}$ is related to the $\mathrm{PB} \leftrightarrow \mathrm{PW}$ conversion.

In order to estimate the optimal voltages for coloring and bleaching of different PB layers, the CVs of S25 and S100 PB layers were recorded in a two electrode cell (containing a solution of $0.1 \mathrm{M} \mathrm{HNO}_{3}$ and $0.1 \mathrm{M} \mathrm{KNO}_{3}$ ) using $\mathrm{PB}$ and platinum electrode in the potential range of $-1.8 \mathrm{~V}$ to $+1.0 \mathrm{~V}$ at a scan rate of $2.0 \mathrm{mV} \mathrm{s}^{-1}$, and the representative curves are displayed in Fig. $6 \mathrm{a}$ and b respectively. These CVs are quite different as the published in the extensive literature (also 
Figure S5 of Supporting Information), and are attributed to the different conditions (especially the electrochemical cell) of these two results.

In both experiments, cyclic voltammograms were started at open circuit potential $(-0.11 \mathrm{~V})$ in the cathodic direction. In this potential range, the layer is safe from any shock and rapid color changes. The potential scan rate $\left(2.0 \mathrm{mV} \mathrm{s}^{-1}\right)$ is also slow enough to confirm that the ions have required time to accumulate in the vicinity of the PB layers to reach suitable concentration. This can be resulted in suitable $\mathrm{K}^{+}$ion exchange between $\mathrm{PB}$ films and the electrolyte, which provides PB, PW (Prussian White), Everitt's Salt (ES), PG (Prussian Green) and PX (Prussian Brown) as different oxidation states [37]. In addition, Fig. 6 clearly shows the beauty of the concept of electrochromic materials that their colors and optical properties can be changed during electron and ion exchange under appropriate voltages. The participation of different species is strongly dependent on the applied potential, and the cations can be inserted in different sites in the PB structure $[38,39]$. Also the shape of voltammetric peaks depending on the nature of the solution media [40]. Jerónimo et al proposed that the physicochemical properties of PB films are strongly dependent on the ratio $\mathrm{Fe}^{3+/} \mathrm{Fe}^{2+}$ in the structure [41]. It is well-known that trivalent iron ions are responsible for PB electrochemical reactions. These ions are mainly located in $\mathrm{Fe}^{2+}$ low-spin-CN-Fe ${ }^{3+}$ high-spin and $\mathrm{Fe}^{3+}$ low-spin- $\mathrm{CN}-\mathrm{Fe}^{2+}$ high-spin sites. Furthermore, these ions are also located next to ferrocyanide vacancies in two possible electroactive Fe sites, depending on experimental conditions [42].

For the both different PB layers, the cathodic scan leads to an increase in cathodic current. This is appeared as a shoulder $\left(\mathrm{C}_{1}\right)$ followed by two distinguished peaks $\left(\mathrm{C}_{2}\right.$ and $\left.\mathrm{C}_{3}\right)$ for $\mathrm{S} 25$ sample (Fig. 6a). For S100 sample on the other hand, in the same potential range, three separate peaks $\left(\mathrm{C}_{1}{ }^{\prime}, \mathrm{C}_{2}{ }^{\prime}\right.$ and $\left.\mathrm{C}_{3}{ }^{\prime}\right)$ are observed in the cathodic scan (Fig. 6b). 
In the anodic half cycle two anodic peaks are observed for both samples, $\mathrm{A}_{1} \& \mathrm{~A}_{2}$ for $\mathrm{S} 25$ sample and $\mathrm{A}_{1}{ }^{\prime} \& \mathrm{~A}_{2}{ }^{\prime}$ for $\mathrm{S} 100$ sample. For S100 sample an increase of anodic current compared to the S25 sample is also detected. The values correspond to the all observed peaks are summarized in table 1.

More detailed analysis of cyclic voltammograms were done by comparison between the color of each PB layer appeared in different potential regions (inset of Fig. 6) which are determined with M, N, O, P, Q, R and S points for S25 sample and $\mathrm{M}^{\prime}, \mathrm{N}^{\prime}, \ldots$ points for S100 sample.

According to Fig. 6 there is no obvious color change between $M\left(M^{\prime}\right)$ and N(N') states in both $\mathrm{S} 25$ and $\mathrm{S} 100$ samples, so the $\mathrm{C}_{1}$ peak is attributed to the hydrogen adsorption/absorption in accord with the previous study [41]. By this discussion while at $M\left(M^{\prime}\right)$ the layers are mostly composed of $\mathrm{PB}$, at $\mathrm{N}\left(\mathrm{N}^{\prime}\right)$ the films are made of a mixture of the initial $\mathrm{PB}$ and a modified $\mathrm{PB}$ as a result of inserted protons.

Comparison between the color of $\mathrm{PB}$ layer correspond to the $\mathrm{N}$ and $\mathrm{O}$ points (the same as $\mathrm{N}^{\prime}$ and $\left.\mathrm{O}^{\prime}\right)$ informs that the $\mathrm{C}_{2}\left(\mathrm{C}_{2}^{\prime}\right)$ peak is related to the conversion of insoluble PB to PW as described by Eq. $1[16]$.

$$
\begin{array}{cccc}
\mathrm{Fe}_{4}{ }^{3+}\left[\mathrm{Fe}^{2+}(\mathrm{CN})_{6}\right]_{3}+4 \mathrm{~K}^{+}+4 \mathrm{e}^{-} & \leftrightarrow & \mathrm{K}_{4} \mathrm{Fe}_{4}{ }^{2+}\left[\mathrm{Fe}^{2+}(\mathrm{CN})_{6}\right]_{3} \\
\text { Insoluble PB } & \leftrightarrow & \text { PW }
\end{array}
$$

By increasing the cathodic voltage to $-1.8 \mathrm{~V} / \mathrm{SCE}$ the film becomes more transparent as it is clear by comparison between the color of $\mathrm{O}$ and $\mathrm{P}$ points. Therefore, $\mathrm{C} 3\left(\mathrm{C}_{3}{ }^{\prime}\right)$ peak is probably due to the conversion of soluble PB to ES according to Eq.2 [43,44]

$$
\begin{aligned}
& \mathrm{KFe}^{3+}\left[\mathrm{Fe}^{2+}(\mathrm{CN})_{6}\right]+\mathrm{K}^{+}+\mathrm{e}^{-} \leftrightarrow \mathrm{K}_{2} \mathrm{Fe}^{2+}\left[\mathrm{Fe}^{2+}(\mathrm{CN})_{6}\right] \\
& \text { Soluble PB } \leftrightarrow \quad \text { ES }
\end{aligned}
$$

This discussion is consistent with the results of the EDX analysis, which confirms presence of 
both soluble and insoluble phase of PB on layers.

Eqs. 1\&2 explicitly reveals the difference between PW and ES. In the literature, many researchers use the name of these two compounds and don't differentiate between PW and ES $[43,44]$.

Similar argument is being made for anodic scan. In this case, comparison between the colors correspond to the $\mathrm{P}$ and $\mathrm{Q}$ points of S25 sample ( $\mathrm{P}^{\prime}$ and $\mathrm{Q}^{\prime}$ points of S100 sample) suggests that $\mathrm{A}_{1}\left(\mathrm{~A}_{1}{ }^{\prime}\right)$ peak is the characteristic peak of ES to $\mathrm{PB}$ transition. This transition will occur in the potential range of $-1.12 \mathrm{~V}$ to $+0.25 \mathrm{~V}$ and $-1.10 \mathrm{~V}$ to $0.50 \mathrm{~V}$ for $\mathrm{S} 25$ and $\mathrm{S} 100$ samples respectively. (Fig. 6)

More increasing anodic voltage for S100 sample resulted in production of PG after a partial oxidation according to Eq.3 (see R' point in Fig. 6b), while for S25 sample PB oxidation resulted in Prussian brown (PX) according to Eq. 4 (see R point in Fig. 6a) [44-47].

$$
\begin{aligned}
{\left[\mathrm{Fe}^{3+} \mathrm{Fe}^{2+}(\mathrm{CN})_{6}\right]^{-} } & \rightarrow \mathrm{Fe}^{3+}\left[\left\{\mathrm{Fe}^{3+}(\mathrm{CN})_{6}\right\}_{2 / 3}\left\{\mathrm{Fe}^{2+}(\mathrm{CN})_{6}\right\}_{1 / 3}\right]^{1 / 3}+\frac{2}{3} \mathrm{e}^{-} \\
\mathrm{PB} & \rightarrow \mathrm{PG} \\
{\left[\mathrm{Fe}^{3+} \mathrm{Fe}^{2+}(\mathrm{CN})_{6}\right]^{-} } & \rightarrow\left[\mathrm{Fe}^{3+} \mathrm{Fe}^{3+}(\mathrm{CN})_{6}\right]^{0}+e^{-} \\
\mathrm{PB} \rightarrow \quad & \rightarrow \quad \mathrm{PX}
\end{aligned}
$$

By reversing the cyclic voltammogram from $R\left(R^{\prime}\right)$ point to the $S\left(S^{\prime}\right)$ and finally $M\left(M^{\prime}\right)$ points, it is observed that the PX and PG are not effectively change to PB on the ITO for S25 and S100 samples respectively. This indicate irreversible behaviour of S25 and S100 samples in the potential range of $0.25 \mathrm{~V}$ to $+1.00 \mathrm{~V}$ and $+0.50 \mathrm{~V}$ to $+1.00 \mathrm{~V}$ respectively. In addition, the solubility of these materials ( $\mathrm{PG}$ and $\mathrm{PX}$ ) in aqueous medium might be a reason that PB layer in the form of PG or PX phases are not applicable in electrochromic devices. Therfore, determining a suitable voltage for using PB layers in ECDs has a vital role. 
In this research, the potential of $-1.7 \mathrm{~V}$ was applied for bleaching of all PB layers while as it was discussed previously, maximum suitable voltage for coloring of all PB layers was not the same. The potential of $+0.25 \mathrm{~V}$ that was applied for coloring of S25 and S50 samples was increased to $+0.50 \mathrm{~V}$ for coloring of $\mathrm{S} 75, \mathrm{~S} 100$, and $\mathrm{S} 150$ samples. These voltages are corresponding to the $\mathrm{Q}$ and Q' points, Fig. 6a and b.

\subsection{Spectroscopic analysis for electrochromic layers}

Determining the suitable voltage for bleaching and coloring the electrochromic (PB) layers is one of the most important points that guaranties the much useful applicable of these layers in electrochromic devices. So that in this research, according to previous section, $-1.7 \mathrm{~V}$ determined for bleaching all samples while for coloring $+0.25 \mathrm{~V}$ was used for S25 and S50; and $+0.50 \mathrm{~V}$ was applied to S75, S100 and S150 respectively. This step was done for each sample under especial voltage in a two-electrode cell configurationas described in section 2.3. For each sample the voltage was applied two minutes and immediately UV-vis spectra were recorded. Fig.7 is a comparison between transmittance spectra of S25, S50, S75, S100 and S150 in as-deposited (a), bleached (b) and colored (c) states respectively without any voltage, after two minute applying suitable voltage for bleaching and coloring.

As we expect, in all three modes, increasing deposition time increases film thickness and reduces transparency (Table 3 and Fig. 1). The intense peak appearing at wavelengths around 475 to 495 $\mathrm{nm}$ in Fig. 7a and 7c, confirms the blue color of the PB films and it is in agreement with Fig. 1. On the contrary, in Fig. $7 \mathrm{~b}$ a fairly uniform distribution in the visible range of the transmittance spectrum of all samples confirms the reduction of color and the increase of transparency, especially in the thinner layers. 
Comparing the transmittance spectrum of the samples in the as-deposited and the color mode shows the peaks are sharper for the colored mode that is as a result of ion exchange between the layer and the electrolyte under applying suitable voltage. Comparing the figures $7 \mathrm{a}, \mathrm{b}$, and $\mathrm{c}$ one can simply observe a small shift of peak wavelength towards the higher wavelengths happened upon increasing deposition time in the bleaching state, which is not significant in the other modes.

Another noticeable point concerning Fig. 7c is that the thinner samples (S25 and S50) showed higher transmittance in the IR reigon which affects on application of these samples in different devices. The device that made with this kind of layers probably path thermal energy [48].

The performance of the layers was evaluated over the 400 to $900 \mathrm{~nm}$ wavelength range, in terms of electrochromic contrast ( $\left.\Delta T_{\mathrm{VIS}}\right)$ in percent at a given wavelength, contrast ratio (CR) and optical density ( $\left.\triangle O D_{\mathrm{VIS}}\right)$ defined as Eqs. 5, 6, and 7.

$\Delta T_{\lambda}=T_{\text {bleached }}-T_{\text {colored }}$

$C R_{\lambda}=T_{\text {bleached }} / T_{\text {colored }}$

$\triangle O D_{\lambda}=\log (C R)$

These parameters obviously present the ability of optical modulation during coloration-bleaching process. On the other word, they result from the variation of layers' absorption [32, 46, 47].

Fig. 8 shows the comparison between $\Delta T$ (a) and $\Delta O D_{\lambda}$ (b) vs. $\lambda$ for all samples. It is seen (in Fig. 8a and Table 2) that $\Delta T_{\max }$ is occurred at different wavelengths $\left(\lambda_{\max }\right)$ for different samples. These differences might be originated from composition and structural nature of the samples.On the other hand, the external applied voltage for switching between colored and bleached state should be effective. These factors directly affect on electrochemical reduction inside the layers 
and also indirectly influence on color and optical properties of them. Fig. 8a shows that $\lambda_{\mathrm{m}}$ normally shifts to lower values by increasing the deposition time of PB layers and maximum value of $\Delta T_{\max }$ is about $76 \%$ for $\mathrm{S} 75$ at $615.6 \mathrm{~nm}$.

From the other point of view, Fig. $8 \mathrm{~b}$ shows the behavior of $\triangle O D_{\lambda}$ and indirectly the $C R$ of all PB layers in same wavelength range. As it can be seen, all of the samples except S150 have a maximum $\triangle O D$ value around $700 \mathrm{~nm}$, that $C R_{\lambda=700 \mathrm{~nm}}$ and $\triangle O D_{\lambda=700 \mathrm{~nm}}$ have respectively changed from 5.60 to 52.51 and 0.74 to 1.72 by increasing the deposition time from $25 \mathrm{~s}$ to $100 \mathrm{~s}$. The observed deviation from this treatment in the S150 can be related to the agglomerated structure of this sample, which limits the ion exchange, so that for S150 the maximum values of $C R$ and $\triangle O D$ reduced to 38.44 and 1.58 , respectively.

Similar analysis has been done by J. Velevska et al. [47] for the PB layer prepared by two step chemical deposition. Although a simple comparison confirms the similarity of the overall behavior of the $\mathrm{CR}_{\lambda}$ and $\triangle O D_{\lambda}$ vs. wavelength for the layers, it is noticeable that in the present research the special method of film preparation by controlling deposition time can lead to an increase of 9.38 times of the $\mathrm{CR}$ and corresponding values for $\triangle O D$.

More accurate study was done at $555 \mathrm{~nm}$, and $633 \mathrm{~nm}$ which are the wavelengths to whichthen human eye has maximum sensitivity (green region) under abundant illumination (daylight) and red diode laser, respectively. The results of this study is summarized in table 3 . It is seen at both $555 \mathrm{~nm}$ and $633 \mathrm{~nm}$, the $\mathrm{S} 75$ attained the maximum value of electrochromic contrast that is 55.36 and 73.62, respectively.

Inserted charge density $\left(Q_{\text {in }}\right)$ and coloration efficiency $(C E)$, as important parameters, while discussing about optical modulation, can be calculated using Eq. 7 and Eq. 8. It may be 
mentioned that $\mathrm{CE}$ is more important than the other parameters from energy consumption point of view $[32,48]$.

$Q_{\text {in }}=\int_{0}^{120} \frac{\mathrm{I}}{\mathrm{A}} d t$

$C E=\frac{\Delta(O D)}{Q_{\text {in }}}$

Where $I$ is current, $t$ is time, and $A$ is area. Table 4 contains $Q_{\text {in }}$ and $C E$ for S25 and S75 as two different kinds of PB layers in three special wavelengths. No significant difference in the order of $\mathrm{CE}$ is observed. It is interesting to note that by increasing the deposition time from $25 \mathrm{~s}$ to $75 \mathrm{~s}$ the $\mathrm{Q}_{\text {in }}$ and $\triangle O D$ increased nearly in the same rate, so that their ratio $(\mathrm{CE})$ didn't change significantly.

\subsection{Double step chronoamperometry analysis}

Repeated double step chronoamperometry has been done for S25, S75, and S150 PB layers in order to study the switching response [49]. For this purpose, a designed periodic square potential according to Fig. 9a was applied to these layers. This experiment has been carried out in a twoelectrode cell as explained in section 2.3. The potential of $-1.7 \mathrm{~V}$ was applied for bleaching of all PB layers while coloring of the layers was done under the potentials of $0.25 \mathrm{~V}$ and $0.5 \mathrm{~V}$ for thinner (S25 and S50) and thicker (S75, S100, and S150) samples, respectively. Fig. 9b shows variation of current density vs. time during the coloration-bleaching process. The amount of potassium charge interchanged between the PB layers and the electrolyte was calculated by integration of current density [50].

This analysis has been done for 10 cycles which the first one was as pretreatment and the results of the second to tenth cycles are presented in Fig. 9. Fig. 9c shows the exchange charge density for both coloring (c) and bleaching (b) processes during oxidation and reduction in the $\mathrm{i}^{\text {th }}$ half 
cycle for each sample. After activation of the layers in the first cycle, by more cycling the exchanged charge became stable. This treatment confirms that these layers can be useful in ECDs because of their high stability after cycling. It is found from Fig. $9 \mathrm{~b}$ and $\mathrm{c}$ that increasing the deposition time resulted in increasing the absolute value of exchanged ions in each half cycle. Another important point to consider is the ratio of coloring to bleaching $\left(\mathrm{Q}_{c} / \mathrm{Q}_{\mathrm{b}}\right)$ exchanged charges. Fig. 9d shows variations of this parameter for different PB samples vs. cycle number. It is observed that, this parameter is lower than unity which confirms that in all cycles the amount of extracted ions is lower than that of inserted ions. Considering the figure, while the difference between $\mathrm{Q}_{\mathrm{c}} / \mathrm{Q}_{\mathrm{b}}$ ratio of $\mathrm{S} 25$ and those of $\mathrm{S} 75$ and $\mathrm{S} 150$ is appreciable, but it is not the case for thicker samples. It confirmes the higher stability of S75 and S150 samples with cycling compared to S25 sample.

\section{Conclusion}

Controlling the deposition time in chronoamperometery method showed to have significant effects on composition, structure, and morphology of electrodeposited PB layers. Hence, in the present investigation among different deposition times $(25,50,75,100$, and $150 \mathrm{~s})$ the sample prepared at $75 \mathrm{~s}$ deposition time was found to content the lowest amount of potassium which confirms the formation of a high purity insoluble PB layer. The FESEM and EDX results showed that more accessible electroactive units in the layers were obtained upon increasing the deposition time. A special non-uniformity due to the propagation of PB particles in a network of cracks was found to facilitate the insertion/extraction of $\mathrm{K}^{+}$ions of electrolyte into the film structure, which is not possible through the S25 sample with compact PB layer morphology. 
In addition, by an exact two electrode $\mathrm{CV}$ experiment, $0.5 \mathrm{~V}$ and $0.25 \mathrm{~V}$ were respectively found to be the optimal voltages for coloring of thick (S75, S100, and S150) and thin (S25 and S50) layers, while $-1.7 \mathrm{~V}$ estimated as the suitable voltage for bleaching all PB layers. Using this interesting and exact method, enabled us to prevent the formation of unstable modes of PB (PX and PG) that is an important point in applying this type of layers in ECDs. Another important of the prepared layers is their semi amorphous nature wich confirmed by the XRD results.

The ability to access high values of electrochromic contrast $(\Delta \mathrm{T})$ in different $\lambda_{\mathrm{m}}$ by controlling the deposition time and external voltage, are the key points of this research. Double step chronoamperometry analysis under optimum voltages showed high stability after cycling, specially for thicker (S75 and S150) layers.

\section{Acknowledgement}

The authors are grateful Physical Chemistry Lab of Department of Chemistry, Semnan University, P.O. Box: 35131-19111, Semnan, Iran for helpful collaboration.

The authors also acknowledgement FEDER, through COMPETE and Fundação para a Ciência e a Tecnologia (FCT) Pest-OE/QUI/UI0616/2014 and the project LUMECD (POCI-01-0145FEDER-016884.

\section{References}

[1] D.R. Rosseinsky, R.J. Mortimer, Electrochromic systems and the prospects for devices, Advanced Materials, 13 (2001) 783-793.

[2] C.G. Granqvist, M.A. Arvizu, I.B. Pehlivan, H.-Y. Qu, R.-T. Wen, G.A. Niklasson, Electrochromic materials and devices for energy efficiency and human comfort in buildings: A critical review, Electrochimica Acta, 259 (2018) 1170-1182. 
[3] M.A. Cardoso, R. Leones, L.C. Rodrigues, M. Fernandes, F.L. Figueiredo, S.C. Nunes, M.M. Silva, V. de Zea Bermudez, Di-ureasil Hybrid Electrolytes Incorporating a New Proton Ionic Liquid, ChemElectroChem, 3 (2016) 783-789.

[4] L. Ponez, F. Sentanin, S. Majid, A. Arof, A. Pawlicka, Ion-conducting membranes based on gelatin and containing LiI/I2 for electrochromic devices, Molecular Crystals and Liquid Crystals, 554 (2012) 239-251.

[5] J.R. Platt, Electrochromism, a possible change of color producible in dyes by an electric field, The Journal of Chemical Physics, 34 (1961) 862-863.

[6] P. Monk, R. Mortimer, D. Rosseinsky, Electrochromism and electrochromic devices, Cambridge University Press2007.

[7] P.M. Monk, R.J. Mortimer, D.R. Rosseinsky, Electrochromism: fundamentals and applications, John Wiley \& Sons2008.

[8] K. Itaya, I. Uchida, V.D. Neff, Electrochemistry of polynuclear transition metal cyanides: Prussian blue and its analogues, Accounts of Chemical Research, 19 (1986) 162-168.

[9] P.R. Somani, S. Radhakrishnan, Electrochromic materials and devices: present and future, Materials chemistry and physics, 77 (2003) 117-133.

[10] F. Herren, P. Fischer, A. Ludi, W. Hälg, Neutron diffraction study of Prussian Blue, Fe4 [Fe (CN) 6] 3. xH2O. Location of water molecules and long-range magnetic order, Inorganic Chemistry, 19 (1980) 956-959.

[11] N.R. de Tacconi, K. Rajeshwar, R.O. Lezna, Metal hexacyanoferrates: electrosynthesis, in situ characterization, and applications, Chemistry of Materials, 15 (2003) 3046-3062.

[12] D.M. DeLongchamp, P.T. Hammond, High-contrast electrochromism and controllable dissolution of assembled Prussian blue/polymer nanocomposites, Advanced Functional Materials, 14 (2004) 224-232.

[13] K. Itaya, N. Shoji, I. Uchida, Catalysis of the reduction of molecular oxygen to water at Prussian blue modified electrodes, Journal of the American Chemical Society, 106 (1984) 34233429.

[14] J. Li, J.D. Qiu, J.J. Xu, H.Y. Chen, X.H. Xia, The Synergistic Effect of Prussian-BlueGrafted Carbon Nanotube/Poly (4-vinylpyridine) Composites for Amperometric Sensing, Advanced Functional Materials, 17 (2007) 1574-1580.

[15] A.A. Karyakin, Prussian blue and its analogues: electrochemistry and analytical applications, Electroanalysis: An International Journal Devoted to Fundamental and Practical Aspects of Electroanalysis, 13 (2001) 813-819.

[16] E. Zolotukhina, I. Bezverkhyy, M. Vorotyntsev, One-stage periodical anodic-cathodic double pulse deposition of nanocomposite materials. Application to Prussian Blue/polypyrrole film coated electrodes, Electrochimica Acta, 122 (2014) 247-258.

[17] R. Koncki, O.S. Wolfbeis, Composite films of Prussian Blue and N-substituted polypyrroles: fabrication and application to optical determination of $\mathrm{pH}$, Analytical chemistry, 70 (1998) 2544-2550.

[18] A.A. Karyakin, E.E. Karyakina, L. Gorton, On the mechanism of $\mathrm{H} 2 \mathrm{O} 2$ reduction at Prussian Blue modified electrodes, Electrochemistry Communications, 1 (1999) 78-82.

[19] A.V. Borisova, E.E. Karyakina, S. Cosnier, A.A. Karyakin, Current-Free Deposition of Prussian Blue with Organic Polymers: Towards Improved Stability and Mass Production of the Advanced Hydrogen Peroxide Transducer, Electroanalysis: An International Journal Devoted to Fundamental and Practical Aspects of Electroanalysis, 21 (2009) 409-414. 
[20] D.R. Rosseinsky, A. Glidle, EDX, spectroscopy, and composition studies of electrochromic iron (III) hexacyanoferrate (II) deposition, Journal of The Electrochemical Society, 150 (2003) C641-C645.

[21] D.R. Rosseinsky, L. Glasser, H.D.B. Jenkins, Thermodynamic clarification of the curious ferric/potassium ion exchange accompanying the electrochromic redox reactions of Prussian blue, iron (III) hexacyanoferrate (II), Journal of the American Chemical Society, 126 (2004) 10472-10477.

[22] P.R. Bueno, F.F. Ferreira, D. Giménez-Romero, G. Oliveira Setti, R.C. Faria, C. Gabrielli, H. Perrot, J.J. Garcia-Jareño, F. Vicente, Synchrotron structural characterization of electrochemically synthesized hexacyanoferrates containing $\mathrm{K}+$ : a revisited analysis of electrochemical redox, The Journal of Physical Chemistry C, 112 (2008) 13264-13271.

[23] F.F. Ferreira, P.R. Bueno, G.O. Setti, D. Giménez-Romero, J.J. García-Jareño, F. Vicente, Resonant $\mathrm{x}$-ray diffraction as a tool to calculate mixed valence ratios: Application to Prussian Blue materials, Applied Physics Letters, 92 (2008) 264103.

[24] A. Roig, J. Navarro, J. Garcia, F. Vicente, Voltammetric study of the stability of deposited Prussian blue films against succesive potential cycling, Electrochimica acta, 39 (1994) 437-442.

[25] C. Lundgren, R.W. Murray, Observations on the composition of Prussian blue films and their electrochemistry, Inorganic Chemistry, 27 (1988) 933-939.

[26] D. Grier, G. McCarthy, North Dakota State University, Fargo, North Dakota, USA, ICDD Grant-in-Aid 1991, Powder Diffraction File, International Center for Diffraction Data, (1994).

[27] L. Chang, S. Chang, W. Chen, W. Han, Z. Li, Z. Zhang, Y. Dai, D. Chen, Facile one-pot synthesis of magnetic Prussian blue core/shell nanoparticles for radioactive cesium removal, RSC Advances, 6 (2016) 96223-96228.

[28] T. Kim, C. Choi, T. Jeong, K. Shim, Influence of Substrate Temperature and O 2 Flow on the Properties of RF-Magnetron-Sputtered Indium-Tin-Oxide Thin Films, JOURNAL-KOREAN PHYSICAL SOCIETY, 51 (2007) 534.

[29] H.R. Fallah, M. Ghasemi, A. Hassanzadeh, H. Steki, The effect of deposition rate on electrical, optical and structural properties of tin-doped indium oxide (ITO) films on glass at low substrate temperature, Physica B: Condensed Matter, 373 (2006) 274-279.

[30] F.-X. Bu, M. Hu, W. Zhang, Q. Meng, L. Xu, D.-M. Jiang, J.-S. Jiang, Three-dimensional hierarchical Prussian blue composed of ultrathin nanosheets: enhanced hetero-catalytic and adsorption properties, Chemical Communications, 51 (2015) 17568-17571.

[31] F.-X. Bu, C.-J. Du, Q.-H. Zhang, J.-S. Jiang, One-pot synthesis of Prussian blue superparticles from reverse microemulsion, CrystEngComm, 16 (2014) 3113-3120.

[32] Y. Chen, Z. Bi, X. Li, X. Xu, S. Zhang, X. Hu, High-coloration efficiency electrochromic device based on novel porous TiO2@ Prussian blue core-shell nanostructures, Electrochimica Acta, 224 (2017) 534-540.

[33] S. Vahur, A. Teearu, I. Leito, ATR-FT-IR spectroscopy in the region of 550-230 cm- 1 for identification of inorganic pigments, Spectrochimica Acta Part A: Molecular and Biomolecular Spectroscopy, 75 (2010) 1061-1072.

[34] A.M. Farah, F.T. Thema, E.D. Dikio, Electrochemical detection of hydrogen peroxide based on graphene oxide/prussian blue modified glassy carbon electrode, Int. J. Electrochem. Sci, 7 (2012) 5069-5083.

[35] L. Lin, X. Huang, L. Wang, A. Tang, Synthesis, characterization and the electrocatalytic application of prussian blue/titanate nanotubes nanocomposite, Solid State Sciences, 12 (2010) 1764-1769. 
[36] R.J.Mortimer, J.R. Reynolds, In situ colorimetric and composite coloration efficiency measurements for electrochromic prussian blue, Journal of Materials Chemistry, 15 (2005) 22262233.

[37] J. Velevska, M.P. Gjorgjevich, N. Stofanov, M.Najdoski ,Electrochromic properties of prussian blue thin films prepared by chemical deposition method, International Journal of Sciences: Bassic and Applied Research, 25(3) (2016) 380-392.

[38] D. Gimenez-Romero, P.R. Bueno, C. Gabrielli, J. Garcia-Jareno, H. Perrot, F. Vicente, Kinetic Aspects of Ion Exchange in $\mathrm{K}$ h Fe k [Fe (CN) 6] $1 \odot \mathrm{m} H 2 \mathrm{O}$ Compounds: A Combined Electrical and Mass Transfer Functions Approach, The Journal of Physical Chemistry B, 110 (2006) 19352-19363.

[39] D. Gimenez-Romero, P.R. Bueno, J. Garcia-Jareno, C. Gabrielli, H. Perrot, F. Vicente, Thermodynamic Aspects of Ion Intercalation in $\mathrm{K} \mathrm{h} \mathrm{Fe} \mathrm{k} \mathrm{[Fe} \mathrm{(CN)} \mathrm{6]} 1 \odot$ m H2O Compounds: Application to the Everit's Salt/Prussian Blue Transition, The Journal of Physical Chemistry B, 110 (2006) 19364-19368.

[40] A. Roig, J.J. Garcia, J. Navarro, R. Tamarit, F. Vicente, Ann. Quim, 89 (1993) 660-662.

[41] J. Agrisuelas, J.J. García-Jareno, F. Vicente, Identification of processes associated with different iron sites in the Prussian Blue structure by in situ electrochemical, gravimetric, and spectroscopic techniques in the dc and ac regimes, The Journal of Physical Chemistry C, 116 (2012) 1935-1947.

[42] J. Agrisuelas, J. García-Jareño, C. Moreno-Guerrero, A. Roig, F. Vicente, Identification of electroactive sites in Prussian Yellow films, Electrochimica Acta, 113 (2013) 825-833.

[43] L. Assis, L. Ponez, A. Januszko, K. Grudzinski, A. Pawlicka, A green-yellow reflective electrochromic device, Electrochimica Acta, 111 (2013) 299-304.

[44] S. Demiri, M. Najdoski, J. Velevska, A simple chemical method for deposition of electrochromic Prussian blue thin films, Materials Research Bulletin, 46 (2011) 2484-2488.

[45] R.J. Mortimer, D.R. Rosseinsky, Electrochemical polychromicity in iron hexacyanoferrate films, and a new film form of ferric ferricyanide, Journal of Electroanalytical Chemistry and Interfacial Electrochemistry, 151 (1983) 133-147.

[46] R.M. Goncalves, H. Kellawi, D.R. Rosseinsky, Electron-transfer processes and electrodeposition involving the iron hexacyanoferrates studied voltammetrically, Journal of the Chemical Society, Dalton Transactions, (1983) 991-994.

[47] J. Velevska, M. Pecovska-Gjorgjevich, N. Stojanov, M. Najdoski, Electrochromic Properties of Prussian Blue Thin Films Prepared by Chemical Deposition Method, International Journal of Sciences: Basic and Applied Research (IJSBAR), 25 (2016) 380-392.

[48] L. Yang, D. Ge, J. Zhao, Y. Ding, X. Kong, Y. Li, Improved electrochromic performance of ordered macroporous tungsten oxide films for IR electrochromic device, Solar Energy Materials and Solar Cells, 100 (2012) 251-257.

[49] E.A. Duek, M.A. De Paoli, M. Mastragostino, An electrochromic device based on polyaniline and prussian blue, Advanced Materials, 4 (1992) 287-291.

[50] D. Vernardou, E. Spanakis, N. Katsarakis, E. Koudoumas, Electrodeposition of V2O5 using ammonium metavanadate at room temperature, Advanced Materials Letters, 5 (2014) 569-572. 


\section{Figures captions}

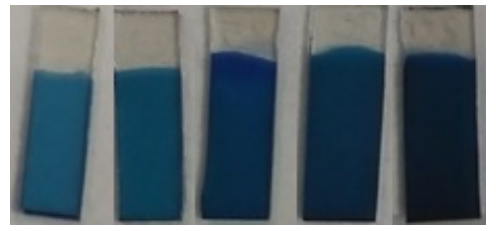

Fig. 1 Physical appearance of samples prepared by chronoamperometry method (left to right S25, S50, S75, S100 and S150).

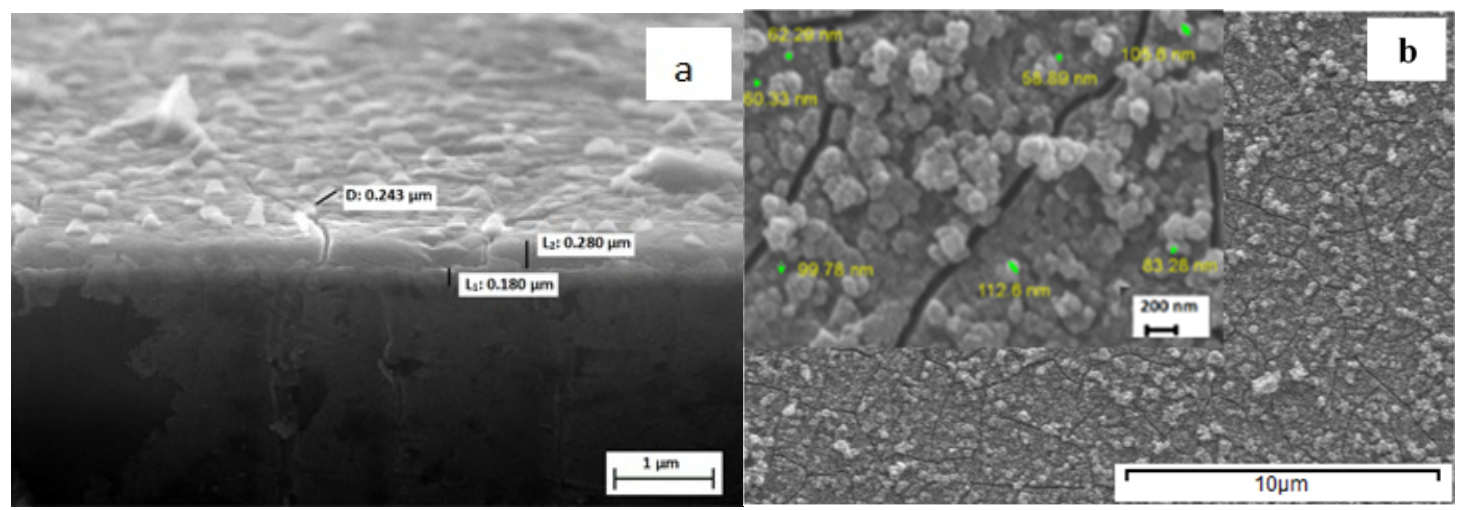

Fig. 2 Cross section (a) and surface (b) FE-SEM view of as deposited S75 in two different magnifications.

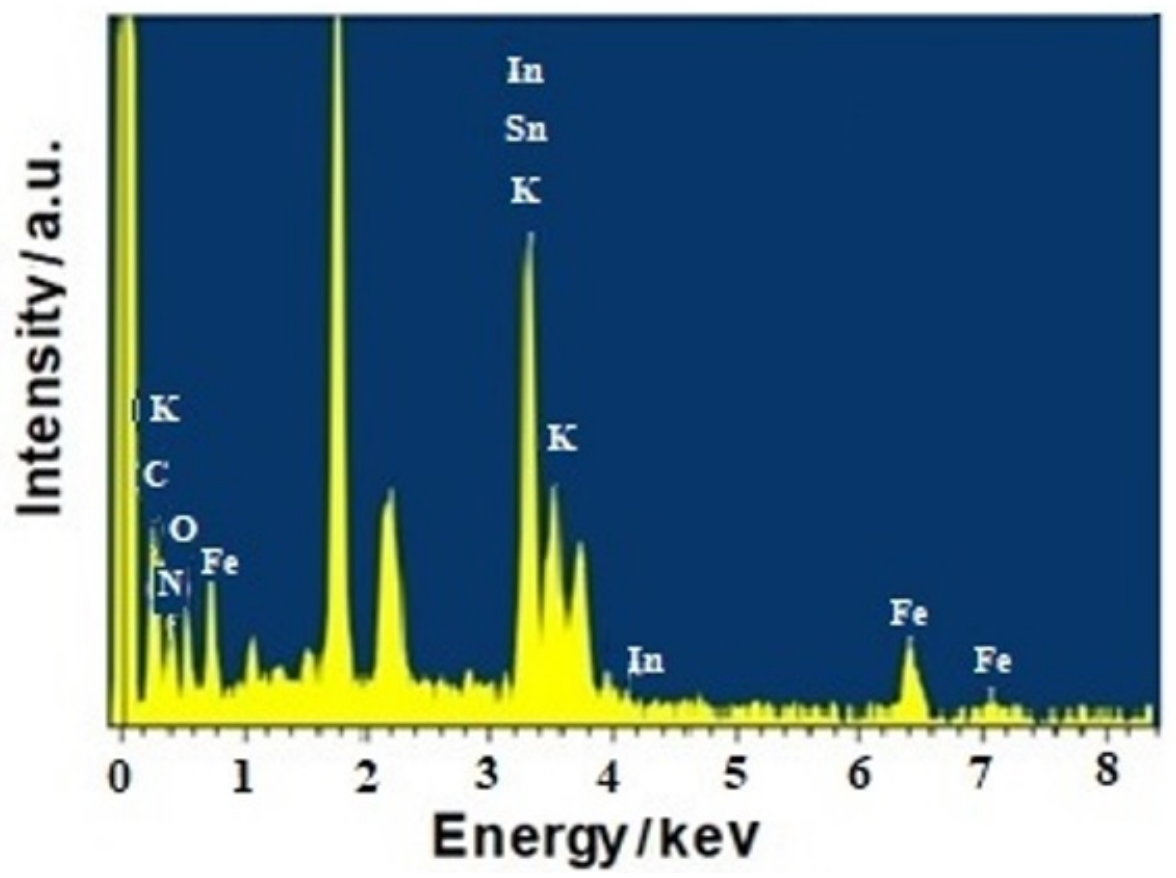

\begin{tabular}{|c|c|c|}
\hline Element & $\begin{array}{c}\text { Weight } \\
(\%)\end{array}$ & $\begin{array}{c}\text { Atomic } \\
(\%)\end{array}$ \\
\hline $\mathrm{C}$ & 10.30 & 20.32 \\
\hline $\mathrm{N}$ & 23.05 & 38.96 \\
\hline $\mathrm{O}$ & 19.52 & 28.90 \\
\hline $\mathrm{K}$ & 2.37 & 1.43 \\
\hline $\mathrm{Fe}$ & 5.59 & 2.37 \\
\hline $\mathrm{In}$ & 30.24 & 6.24 \\
\hline Sn & 8.93 & 1.78 \\
\hline Total & 100 & \\
\hline
\end{tabular}

Fig. 3 EDX spectrum of S75 PB layer 


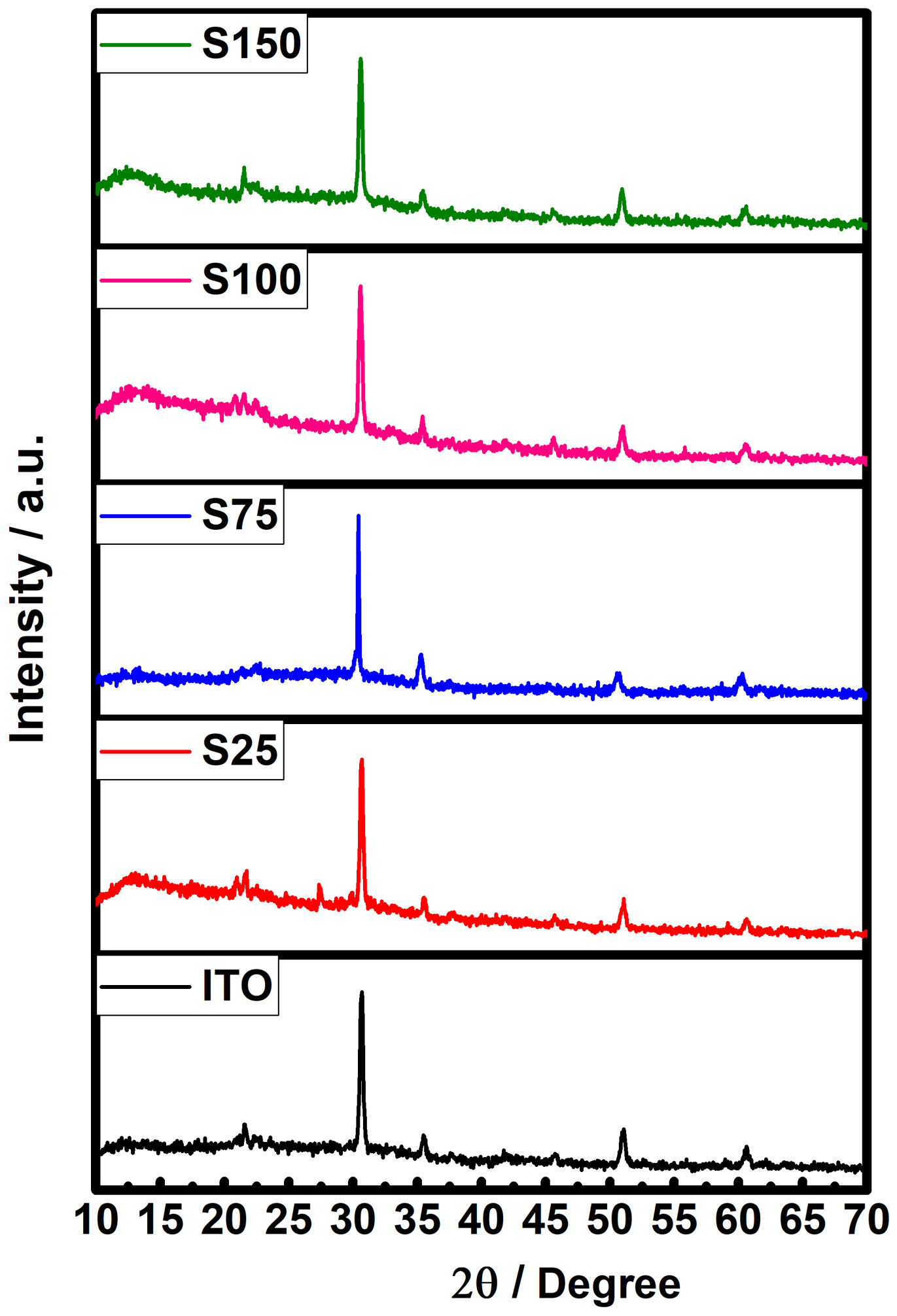


Fig. 4. XRD patterns of bare ITO and different PB layers (S25, S75, S100, and S150) on ITO substrate

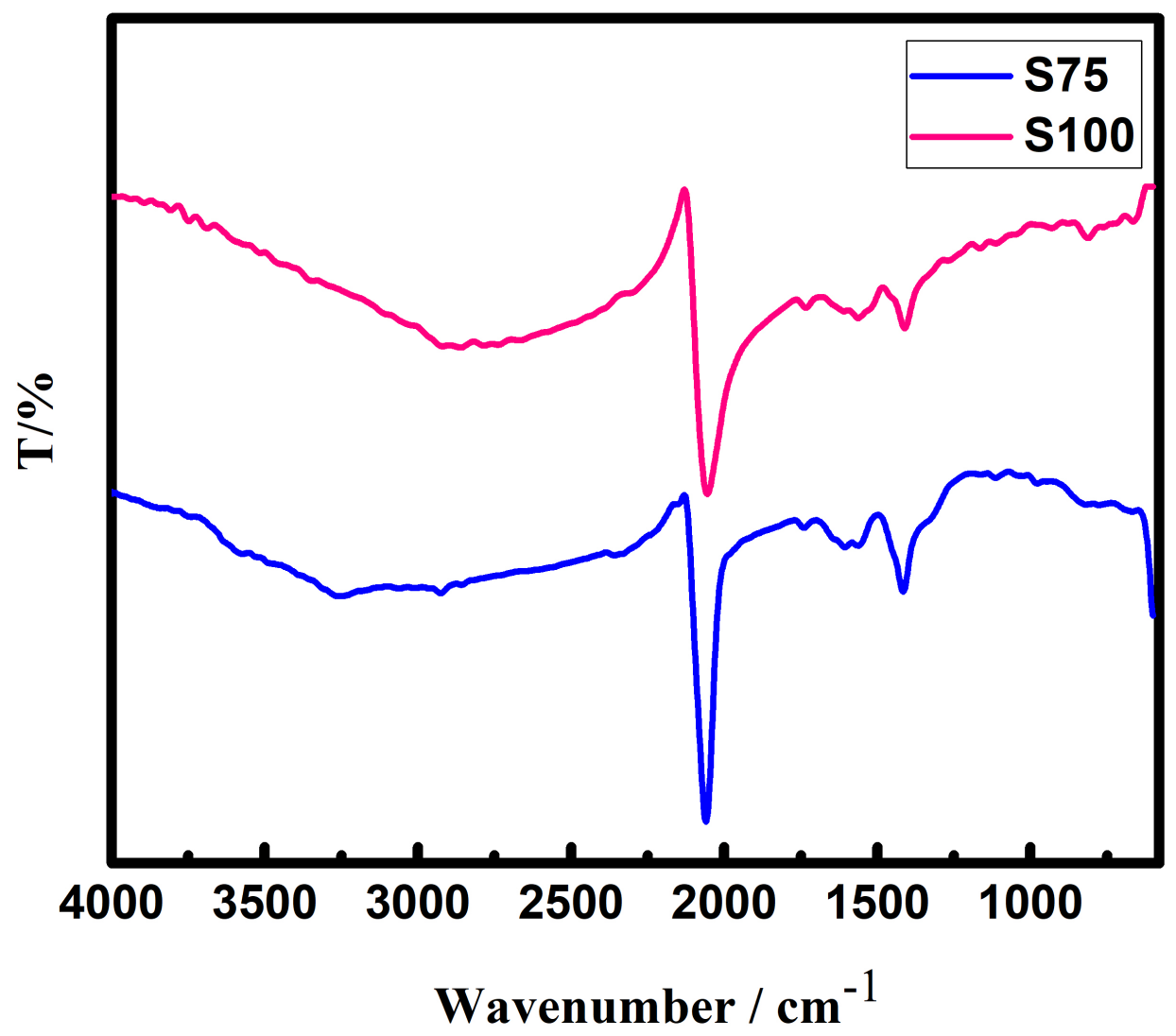

Fig. 5 FTIR-ATR spectra of S75 and S100 PB layers
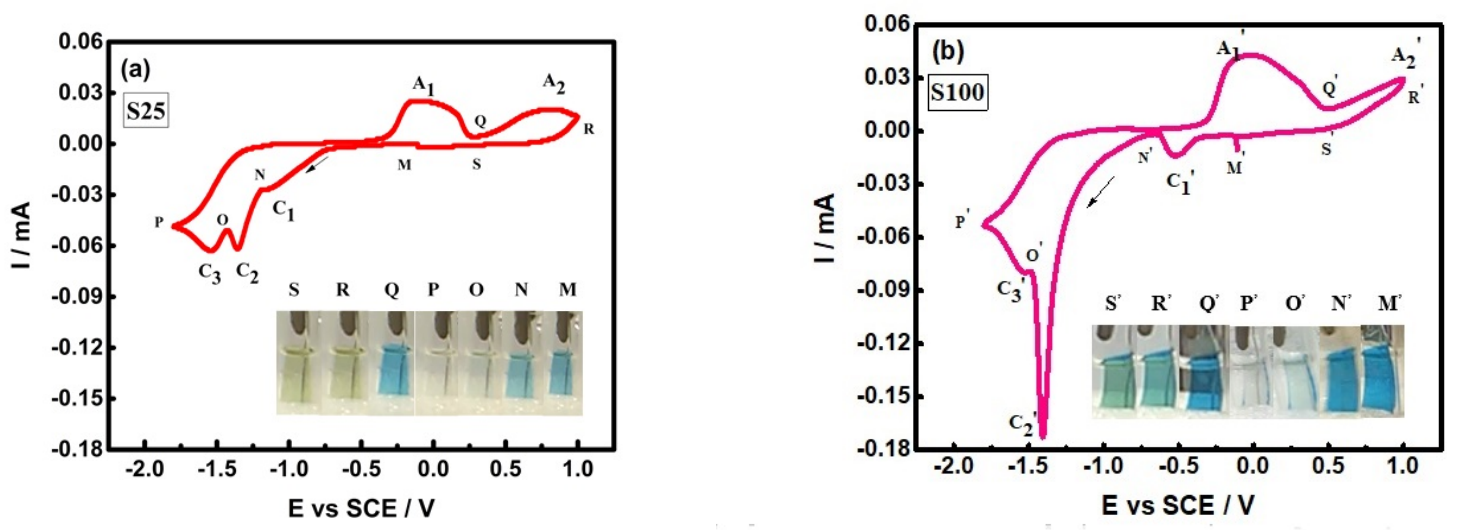
Fig. 6 The CV response of S25 (a) and S100 (b) as two different thickness PB layers in a mixture solution of $\mathrm{HNO} 3(100 \mathrm{mM})$ and $\mathrm{KNO}_{3}(100 \mathrm{mM})$ as electrolyte under $2.0 \mathrm{mV} \mathrm{s}-1$ scan rate and corresponding images.
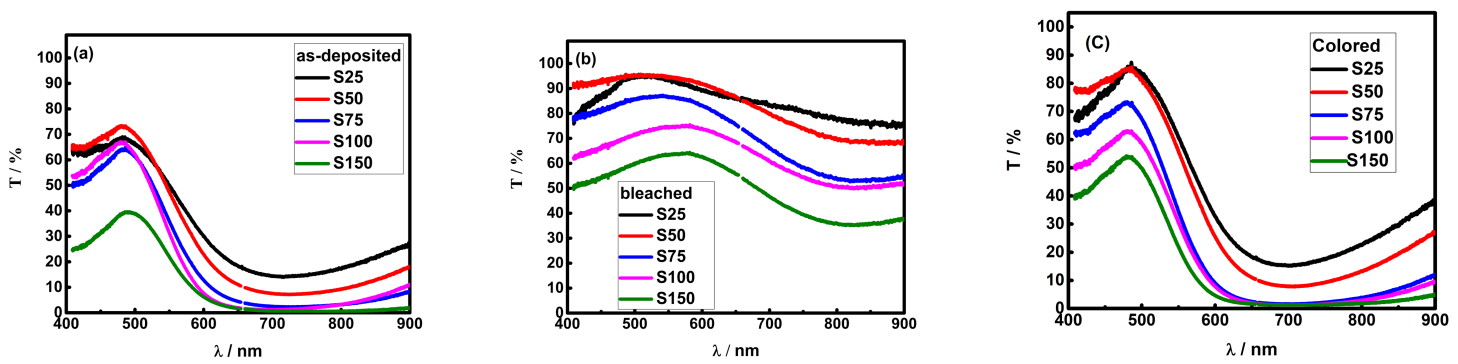

Fig. 7 Comparison between transmittance spectra of S25, S50, S75, S100 and S150 in asdeposited (a), bleached (b) and colored (c) states.
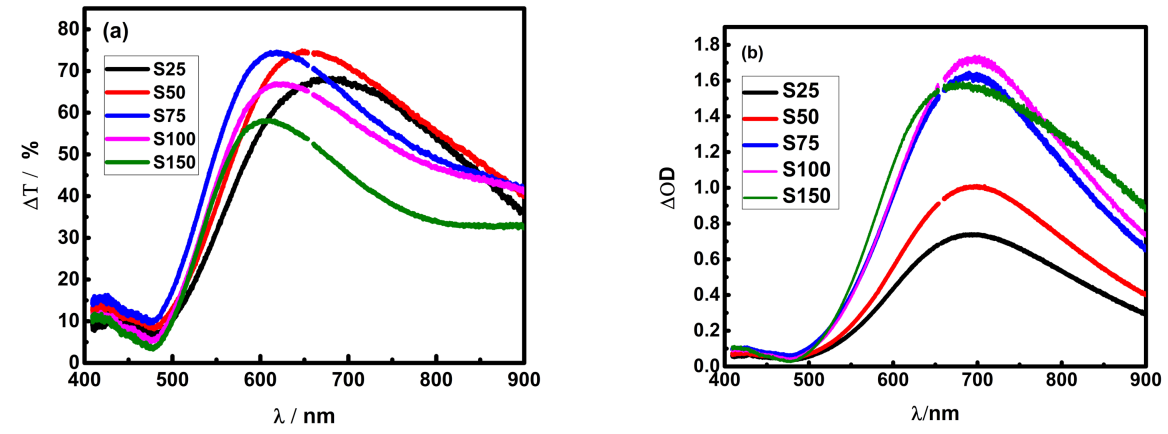

Fig. 8 Comparison between electrochromic contrast $(\Delta \mathrm{T})$ (a) and change of optical density $(\Delta \mathrm{OD})(\mathrm{b})$ vs. wavelength of S25, S50, S75, S100 and S150 which are evaluated from colored and bleach states transmittance. 

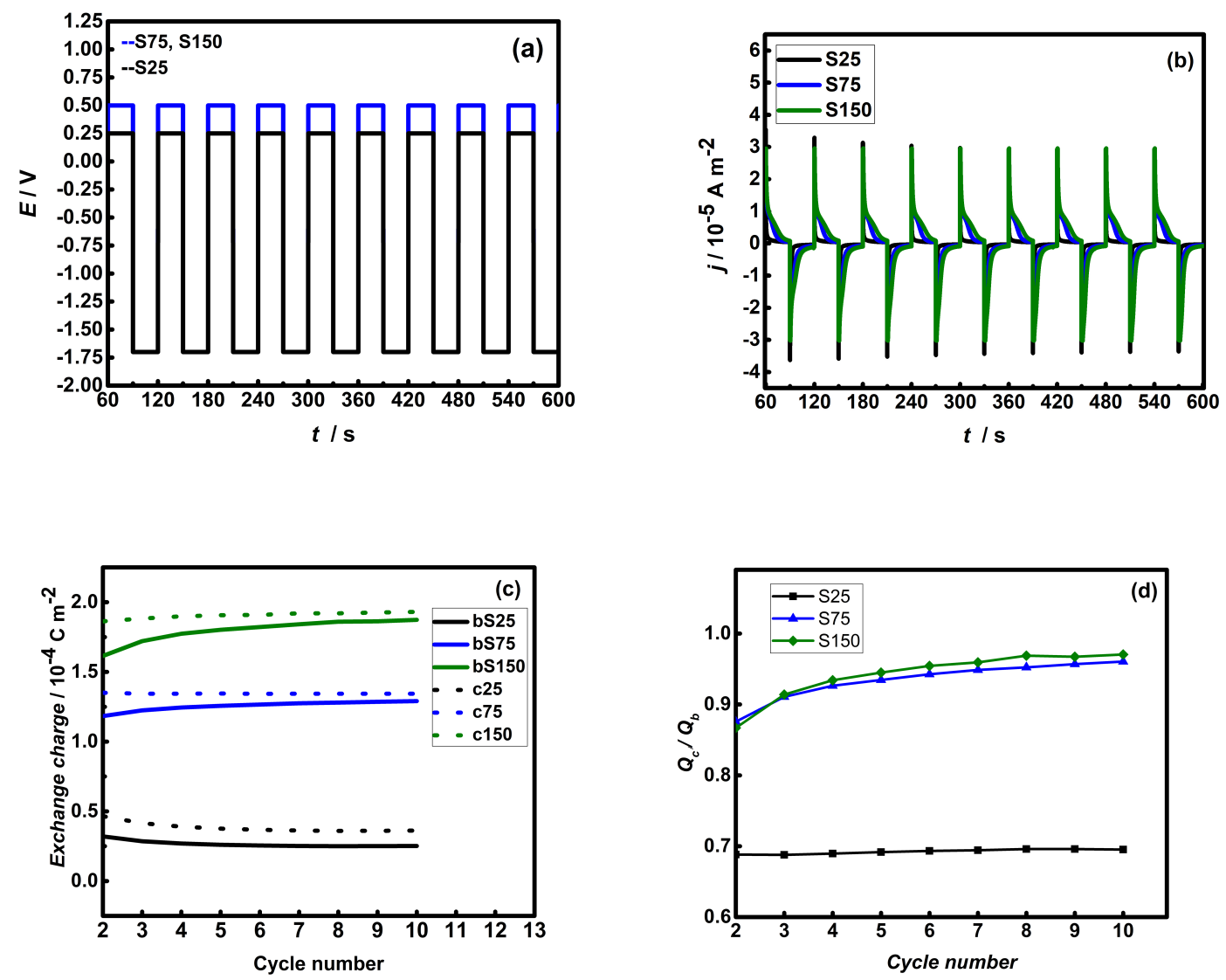

Fig. 9 Comparison between double step periodic potential (a) and chronoamperometric response (b) vs. time, exchange charge during coloring (solid lines) / bleaching (Dot lines) (c) and the ratio of coloring to bleaching $\left(\mathrm{Q}_{\mathrm{c}} / \mathrm{Q}_{\mathrm{b}}\right)$ exchange charge vs. cycle numbers (d) for $\mathrm{S} 25$, $\mathrm{S} 75$, and S150 PB sample

\section{Tables captions}

Table 1 Peak and shoulder values (Voltage and Current) corresponding to voltammogram 
analysis

\begin{tabular}{|c|c|c|c|c|c|}
\hline Parameters & \multicolumn{2}{|c|}{ S25 } & \multicolumn{2}{|c|}{ S100 } & Change of colors \\
\hline $\mathrm{V} / \mathrm{V}$ & -1.1389 & \multirow{2}{*}{$\begin{array}{c}\text { Shoulder } \\
C_{1}\end{array}$} & -0.5173 & \multirow{2}{*}{$\begin{array}{l}\text { Peak } \\
C_{1^{\prime}}\end{array}$} & \multirow[t]{2}{*}{ Blue } \\
\hline $1 / \mathrm{mA}$ & -0.0269 & & -0.0139 & & \\
\hline $\mathrm{V} / \mathrm{V}$ & -1.3512 & \multirow{2}{*}{$\begin{array}{c}\text { Peak } \\
\mathrm{C}_{2}\end{array}$} & -1.4080 & \multirow{2}{*}{$\begin{array}{l}\text { Peak } \\
C_{2^{\prime}}\end{array}$} & \multirow[t]{2}{*}{ Blue to bleach } \\
\hline $\mathrm{I} / \mathrm{mA}$ & -0.0620 & & -0.1727 & & \\
\hline $\mathrm{V} / \mathrm{V}$ & -1.5261 & \multirow{2}{*}{$\begin{array}{l}\text { Peak } \\
\mathrm{C}_{3}\end{array}$} & -1.5216 & \multirow{2}{*}{$\begin{array}{l}\text { Peak } \\
\text { C }_{3^{\prime}}\end{array}$} & \multirow[t]{2}{*}{ More bleaching } \\
\hline $\mathrm{I} / \mathrm{mA}$ & -0.0630 & & -0.0799 & & \\
\hline $\mathrm{V} / \mathrm{V}$ & -0.1646 & \multirow{2}{*}{$\begin{array}{c}\text { Peak } \\
A_{1}\end{array}$} & -0.0337 & \multirow{2}{*}{$\begin{array}{c}\text { Peak } \\
A_{1^{\prime}}\end{array}$} & \multirow[t]{2}{*}{ Bleach to blue } \\
\hline $\mathrm{I} / \mathrm{mA}$ & 0.0250 & & 0.0431 & & \\
\hline $\mathrm{V} / \mathrm{V}$ & 0.7301 & \multirow{2}{*}{$\begin{array}{c}\text { Peak } \\
\mathrm{A}_{2}\end{array}$} & - & \multirow{2}{*}{$\begin{array}{c}\text { Peak } \\
A_{2^{\prime}}\end{array}$} & \multirow{2}{*}{$\begin{array}{c}\text { Blue to green / } \\
\text { pale brown }\end{array}$} \\
\hline $1 / \mathrm{mA}$ & 0.0200 & & - & & \\
\hline
\end{tabular}

Table 2 comparison between $\lambda \max$ and $\Delta \mathrm{Tmax}$ of S25, S50, S75, S100 and S150 which are evaluated from colored and bleach states transmittance.

\begin{tabular}{|l|l|l|l|l|l|}
\hline Parameters & S25 & S50 & S75 & S100 & S150 \\
\hline$\lambda_{\max }$ & 672.88 & 648.94 & 615.60 & 614.62 & 610.58 \\
\hline$\Delta T_{\max }$ & 69.87 & 76.34 & 76.23 & 68.43 & 58.09 \\
\hline
\end{tabular}

Table 3 comparison between transmittance in three different state (As-deposited, bleaches and colored), electrochromic contrast and optical density of S25, S50, S75, S100 and S150.

\begin{tabular}{|c|c|c|c|c|c|c|c|c|c|c|}
\hline$\lambda$ & \multicolumn{5}{|c|}{$555 \mathrm{~nm}$} & \multicolumn{5}{c|}{$633 \mathrm{~nm}$} \\
\hline Sample & $T_{\text {As-deposited }}$ & $T_{\text {Bleached }}$ & $T_{\text {Colored }}$ & $\Delta T$ & $\Delta(O D)$ & $T_{\text {As-deposited }}$ & $T_{\text {Bleached }}$ & $T_{\text {colored }}$ & $\Delta T$ & $\Delta(O D)$ \\
& $\%$ & $\%$ & $\%$ & $\%$ & & $\%$ & $\%$ & $\%$ & $\%$ & \\
& & & & & & & & & & \\
\end{tabular}




\begin{tabular}{|c|c|c|c|c|c|c|c|c|c|c|}
\hline S25 & 47.55 & 92.30 & 57.68 & 34.62 & 0.20 & 21.17 & 86.41 & 21.43 & 63.98 & 0.61 \\
\hline S50 & 44.47 & 94.57 & 52.53 & 42.05 & 0.26 & 13.73 & 88.51 & 14.15 & 73.37 & 0.80 \\
\hline S75 & 32.92 & 86.41 & 31.05 & 55.36 & 0.45 & 6.14 & 78.19 & 3.56 & 73.62 & 1.34 \\
\hline S100 & 27.82 & 74.69 & 27.41 & 46.28 & 0.44 & 2.87 & 70.43 & 2.97 & 66.46 & 1.38 \\
\hline S150 & 19.81 & 63.53 & 18.14 & 44.39 & 0.52 & 2.52 & 58.40 & 1.07 & 56.33 & 1.75 \\
\hline
\end{tabular}

Table 4 comparison between charge density $\left(Q_{\text {in }}\right)$ and coloration efficiency $(C E)$ of S25 and S75.

\begin{tabular}{|c|c|c|c|c|}
\hline \multicolumn{2}{|c|}{$\lambda / \mathrm{nm}$} & 555 & 633 & 700 \\
\hline Sample & $Q_{\text {in }} / \mathrm{C} \mathrm{cm}^{-2}$ & $C E / \mathrm{cm}^{2} \mathrm{C}^{-1}$ & $C E / \mathrm{cm}^{2} \mathrm{C}^{-1}$ & $C E / \mathrm{cm}^{2} \mathrm{C}^{-1}$ \\
\hline $\mathrm{S} 25$ & 101.801 & $1.965 \times 10^{-3}$ & $5.992 \times 10^{-3}$ & $7.230 \times 10^{-3}$ \\
\hline $\mathrm{S} 75$ & 211.153 & $2.131 \times 10^{-3}$ & $6.356 \times 10^{-3}$ & $7.663 \times 10^{-3}$ \\
\hline
\end{tabular}

